\title{
Multi-sided platform and data-driven care research
}

\section{A longitudinal case study on business model innovation for improving care in complex neurological diseases}

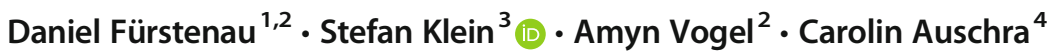

Received: 31 July 2020 / Accepted: 19 January 2021 / Published online: 23 March 2021

(C) The Author(s) 2021

\begin{abstract}
Multi-sided platforms in healthcare often focus their business model on standardizing care for wide-spread, chronic diseases. However, there is a lack of knowledge surrounding platform business models enabling individualized care coordination for patients with rare diseases. This paper analyses the development of a complex platform business model addressing Amyotrophic Lateral Sclerosis, a severe neurological disease that requires the coordination of a diverse network of medical specialists, care, and equipment providers. A longitudinal case study examines the platform's development, focusing subsequently on qualitative and efficient care coordination, care research, and active and direct involvement of patients, as well as establishing two business models, namely, care coordination and care research. We reconstruct how these complex platform business models were configured to improve patient care and care research, thereby creating immediate value for patients and insights for long-term care improvements. The ongoing platform development carefully balances value generation for diverse stakeholders and economic sustainability.
\end{abstract}

Keywords Digital health platform $\cdot$ Business model $\cdot$ Datafication $\cdot$ Value-based health $\cdot$ Rare disease $\cdot$ Care research $\cdot$ Process perspective

JEL classification $\mathrm{I} 1 \cdot \mathrm{M} 1 \cdot \mathrm{O} 3$

\section{Introduction}

In healthcare, digital multi-sided platforms (MSPs) promise to improve intersectoral and interprofessional collaboration among diverse stakeholder groups, with an emphasis on active participation and engagement of patients (Irwin et al. 2014;
Zenooz and Fox 2019). In general, MSPs are defined as systems that create value by enabling direct interactions between two (or more) otherwise distinct parties, such as suppliers and users (Hagiu and Wright 2015). By connecting these parties, they enable cross-side positive network effects, that is, a mutual reinforcement of value for the different sides (Parker et al.

This article is part of the Topical Collection on Digital Healthcare Services

\begin{tabular}{l}
\hline Responsible Editor: Nilmini Wickramasinghe \\
\hline $\begin{array}{l}\text { Daniel Fürstenau } \\
\text { dfu.digi@cbs.dk }\end{array}$ \\
Stefan Klein \\
stefan.klein@uni-muenster.de \\
Amyn Vogel \\
amyn.vogel@ fu-berlin.de \\
Carolin Auschra \\
carolin.auschra@ fu-berlin.de
\end{tabular}

1 Department of Digitalization, Copenhagen Business School, Howitzvej 60, 2000 Frederiksberg, Dänemark

2 Department of Information Systems, Freie Universität Berlin, Garystr. 21, 12435 Berlin, Germany

3 Department of Information Systems, WWU Münster, Leonardo Campus 11, 48149 Münster, Germany

4 Department of Management, Freie Universität Berlin, Garystr. 21, 14195 Berlin, Germany 
2017; Song et al. 2018). MSPs also typically facilitate active participation and prosumption (referring to simultaneous production and consumption) of the connected parties (Xie et al. 2008).

The healthcare platform market is split between highly visible, well researched examples of health MSPs that focus on wide-spread diseases (e.g., Apple Health), and a broader, more differentiated, and less visible group of specialized platforms, which address an array of rare diseases such as amyotrophic lateral sclerosis (ALS), the focus of this paper. Procurement of care products and services is a complex administrative process between patients, general practitioners (GPs), specialized doctors, care centres, hospitals, therapists, providers of assistive technology devices (ATD), pharmacies, and even insurance companies. ALS patients, and their relatives, are often overwhelmed by the complexity and fragmentation of the specialized care offerings, ATDs and medication, while being simultaneously faced with quickly deteriorating conditions in their health (Bakker et al. 2015). Here lies the potential of MSPs.

While several studies have applied the theoretical perspective of MSPs to digital health platforms (Fürstenau et al. 2019; Otto and Jarke 2019; Yaraghi et al. 2015), research on the dynamic configuration of business models focusing on rare diseases is lacking. This is an important issue given that digital health platforms without a viable business model are not sustainable, nor can they deliver services over time or generate value for patients and other stakeholders in the long run. By scrutinizing a single, specialized platform, we aim to reveal how value can be generated for patients with rare and complex diseases. Most platforms include data-driven business models (Guggenberger et al. 2020, p. 7), which analyse data on the operation of the platform, information about the platform users and their transaction-generated-data. These can be used to improve the platform services and operations. Yet, such models can also be used to generate and monetize predictions about users' behavior ('behavioral surplus', see Zuboff 2019). However, patient data is sensitive and protected by privacy law. This creates a conundrum for health care platforms that need both patient data and patients' consent to collect and protect patients and their data in accordance with privacy regulation. Moreover, it is not well understood how datafication, driven by an underlying "data optimism" (Harari 2017), affects MSP business models and complements or interferes with them - especially in the context of healthcare (Kelly and Noonan 2017).

Our case is a specialized platform for patients with rare diseases that uses a business model reliant on patient data. Our research question is: How can multi-sided health platforms enact business models to create value for patients and foster care research in a viable manner? We have done a longitudinal qualitative case study (Yin 2018) following an abductive approach (cf. Alvesson and Kärreman 2007;
Locke et al. 2008). We start with the puzzling fact that very few examples of successful MSPs can be observed in health care, especially in the heavily regulated German healthcare market. We use the theoretical notions of the MSP (Hagiu and Wright 2015) and value-based healthcare (Porter and Teisberg 2006) to document the development towards a complex business model. This paper reconstructs the business model development of Ambulanzpartner.de (APST), a platform serving ALS patients. In line with the recommendations for multidisciplinary ALS care teams (Nagasaka and Takiyama 2015), as well as guidelines for care (Mitchell 2000), APST has developed a platform for case management or concerted care, linking patients and their relatives to medical care providers (therapists, doctors, pharmacists, and care institutions), ATD suppliers, and cost supporters (insurance companies), i.e. a multi-sided coordination platform across multiple stakeholder groups. The platform is patient-centric and orchestrates customized care. Our findings reveal that the platform provider added several extensions to the overarching business model over time that focused on different logics of value creation: the platform had initially started with a business model solely focusing on coordinating the provision of care. The coordination of care implied the digitalization of patient records and transactions from their care service and equipment providers. In turn, data collected by the APST platform became part of a second business model that generates value from (contract) research about ALS and related therapies. Recently, the platform has extended both business models by facilitating direct engagement of patients allowing them to initiate care requests, in addition to monitoring and reporting their health status via a dedicated app in line with patient-centric care.

By examining the instantiation of a platform business model in the context of complex neurological diseases, the paper contributes to 1) knowledge on business model development by MSPs, and 2) to research on value-based health care. As a first contribution, the case illustrates how a digital health platform can develop a complex business model that facilitates inter-professional coordination and cooperation across multiple providers, while generating value for several stakeholders. One analytically distinguishable business model of the platform follows the logic of improving the coordination of care (transactions). A second, closely interwoven business model is in line with a care research logic: transaction data are also used as evidence of care processes. In addition, the platform actively solicits data from patients such as feedback on the quality of care to engage patients, collect data for research, and include these data within the platform's central revenue model. Moreover, this paper shows how platform providers can align different business models in a synergistic manner. As a second contribution, this paper illustrates how health platforms can create patient value, both for the individual patient, as well as entire patient populations, with the generation 
of value from patient data ('datafication'). As ALS does not have a known cure, improving care is the only option for medical care. The researched MSP, thereby, shows how platform providers can enact value generation that balances the needs of its different stakeholders, in contrast to those MSPs that use their primary services to extract value only for the platforms' shareholders-often in opaque ways-by collecting and analysing user data (Mazzucato 2019).

\section{Conceptual background}

\section{Three logics of patient value creation in healthcare}

Our starting point is the concept of value-based healthcare (VBHC) (Porter 2008; Porter and Teisberg 2006), with its main focus on patient value. In our research we define 'patient value' as a multidimensional construct that considers medical and patient-centric outcomes, as well as efficiency aspects. Efficiency, in the sense of cost savings, plays an important role in an increasingly economized health care system and is therefore to be included in the analysis, even though it is not the aim of the case we are studying, but merely a necessary condition for sustainability. The concept of VHBC proposes to consider the quality and design of care in the in the best possible way to increase patient well-being. For this purpose, medical outcomes such as mortality and complication rates, as well as patient-related outcomes such as individual quality of life and functional capacity, are of major importance (ICHOM 2020). Overall, this approach results in three logics towards patient-oriented value generation, which we will discuss in relation to their support via digital platforms (that is, under the premise that access to care should also be critically considered) (Vega 2013; Wickramasinghe et al. 2019).

The medical outcome logic considers an important aspect of the medical discipline, that is, the strive to cure and to provide the best care possible for the patients. To do so, medicine has become increasingly devoted to research, which has resulted in more evidence-based medicine and care (see e.g., Sackett et al. 1996). An important aspect of evidence-based medicine is to translate research into actionable guidelines that can be enacted in medical practices and processes. Much research conducted in medicine is empirical, using randomizedcontrolled trials or other techniques to test new interventions on study subjects. While this was previously limited to restricted patient collectives, digitalization has enabled largescale prospective and retrospective studies using different types of data (evidence), including digital trace data collected on/by digital health platforms. Platforms in the context of rare and highly lethal diseases face the challenge of continually recreating their patient sample (due to a significantly high mortality rate), whose data are captured with the help of the platform.
The patient-related outcome logic extends the medical outcome logic that considers only medical symptoms and their cure. It places greater value on the individual and the quality of treatment. In this context, the patient-related outcome measures (PROMs) and patient-reported experience measures (PREMs) are of great importance when tracking key treatment features, such as quality of life or individual well-being (ICHOM 2020). Platform-based transaction data facilitate comprehensive and contextualized patient-based monitoring of care provision. Digital trace data enables the mining of large data sources for surrogates of patient-centric outcomes and this data may be extended by newly collected digital biomarkers from mobile, wearables, and smart devices (Moghimi et al. 2013; Wickramasinghe and Bodendorf 2019). Together, these three logics explain important facets of patient value creation in healthcare and enable the creation of platformbased business models to be predicated on them.

\section{Business models of multi-sided health platforms}

Multi-sided platforms link two or more stakeholder groups and enable interactions between them (Hagiu and Wright 2015). Theoretical work on MSPs crops up at the intersection of various discourses (Baldwin and Woodard 2009; Gawer and Cusumano 2014), including industry infrastructure (Gawer and Cusumano 2014), platform ecosystems (Ceccagnoli et al. 2012; Parker et al. 2017), modes of networking (Raivio and Luukkainen 2011), cross-side network effects (Anderson et al. 2014; Rochet and Tirole 2003; Song et al. 2018), (development) strategy (van Alstyne et al. 2016), business modeling (Muzellec et al. 2015), and disruptive innovation (Hwang and Christensen 2008; Kazan 2018).

Our research is embedded in the discourse on platform business models. The very notion of a business model highlights the need to adjust, respond and progressively drive the dynamics of digital transformation. Porter (2001) has characterized the notion of business model as "murky at best ... and an invitation to faulty thinking [at worst]", while Foss and Saebi (2018) find that the field of business modelling, even after two decades of research, lacks "cumulative theorizing". Still, business models equate to simply "defining the business" (Abell 1980), with an emphasis on innovation and digital transformation. Prominent depictions, like the business model canvas (Osterwalder and Pigneur 2013), can easily be mistaken as overly simplistic. However, they can also be used as a springboard for ongoing and increasingly complex reflections on key parameters of the business and its development, including a stakeholder view. Business model pattern have been identified and used for classification (Gassmann et al. 2014; Remane et al. 2017).

A platform business model can be defined as the way in which a platform creates, delivers, and captures value for its stakeholders (cf. Täuscher and Laudien 2018; who refer to 
Teece 2010). According to Teece (2010), a business model "articulates the logic and provides data and other evidence that demonstrates how a business creates and delivers value to customers" (p. 173). However, value is neither the "property of an object nor a subjective preference" (Kornberger 2017, p. 1753), instead it is constituted by valuation mechanisms (e.g., rankings, awards, reviews), and, as such, is socially constructed. This is especially important for the study of a platform, which is catering to treatment options for a rare disease; especially so, when, for instance, groups such as patients and sickness funds may value the same outcome very differently (e.g. enhanced life quality, saved costs). Teece's (2010) business model definition can be aligned and further specified using an earlier definition of Timmers' (1998), who suggests that a business model includes potential benefits for various actors (i.e. value creation in Teece's model), as well as "an architecture for product, service, and information flows" (p. 4) (i.e. value delivery in Teece's model), and revenue sources (i.e. value capturing in Teece's model).

\section{Alignment of logics in multi-sided platform business models}

Over time, an MSP's business model may change, innovate (Remane et al. 2017), and/or expand (Hein et al. 2019). One strand of literature focuses especially on the extension of business models and holds that firms can develop multiple business models or business model portfolios. Other authors (e.g., Li 2020), however, also mainly understand platforms as enacting multiple business models per se. Multiple business models allow a firm to enact different ways of delivering "value to its customers to ensure both its medium term viability and future development" (Sabatier et al. 2010, p. 432), therefore it is likely for firms to develop multiple business models, beyond the start-up phase of growth, to reduce risks. Moreover, multiple business models allow for experimentation with certain models while, at the same time, exploiting others for continuous revenue generation.

In most cases, firms add business models that relate to their existing venture - for instance, regarding the existing competencies, technologies, or markets addressed to-date (Sabatier et al. 2010). However, business models that become more complex, and which address an increasing number of stakeholders, may also cause tension and contradictions between stakeholders, and even the business models themselves. Previous research also demonstrates that even platforms with single business models can face numerous tensions that need to be managed. These include, among others, tensions around competition versus cooperation, control versus openness, standardization versus differentiation, platform complexity versus development costs, and short-term value appropriation versus long-term value creation (Mini and Widjaja 2019). It is therefore vital for business model analysts to consider complementary and interfering activities related to a company's business model (Brynjolfsson et al. 1997). Complementary activities are those activities that create synergy, and when present together, enhance value. Interfering activities are those which are conflicting, and in turn, diminish value.

\section{Research design}

We present a single, longitudinal case study, covering the first nine years of a multi-sided platform in healthcare, that aims to create patient value in the context of a rare disease-ALS. To reconstruct the development of this platform and its underlying complex business model, we follow an in-depth, qualitative case study approach (Eisenhardt 1989; Yin 2018). The selected single case is extreme (Yin 2018), as ALS pushes even the most advanced healthcare systems to their limits and, currently, no comparable platforms that address this disease exist. Moreover, this case also provides a reference point for cases studies on platforms focusing on other rare diseases, as such it is a starting point for theoretical generalization (see also Eisenhardt 1989).

\section{Case context and selection}

APST was founded in 2011 to coordinate and enhance treatment for ALS patients. ALS is a severe, relentlessly progressive, and fatal neurodegenerative disease with no known cure. It is characterized by progressive weakness of voluntary muscles for movement as well as those for swallowing, speech and respiration (Soriani and Desnuelle 2017). Most patients suffering from ALS die within 2-4 years after the onset of symptoms due to respiratory failure. Only $5-10 \%$ of patients have a life expectancy of more than ten years (Seitzer et al. 2016). Given the dire prognosis and swift progression of the disease, patients and their relatives are often overwhelmed by the challenges of organizing medical care and dedicated equipment. As one patient representative and affected person (\#11.1) himself described: "The further the disease progresses, the greater the dependence on external help [becomes]." ALS care also faces profound coordination challenges (for a review, see Seitzer et al. 2016):

"The ideal way to deal with the disease is through interdisciplinary hospital teams, with the external support of primary care teams and patient and family associations. These teams generally aim to provide comprehensive, joint care by the various professionals involved in the care of ALS patients. There are various care models, instantiating value-based healthcare. The teams usually include neurologists and respiratory medicine specialists, as well as nurses, physiotherapists and social 
workers, extended by, depending on the resources of each centre, occupational therapists, cardiologists, psychologists, ear, nose and throat specialists, etc., or even in some cases by providing home care. ... The key objectives of these teams are to optimize medical care, facilitate communication between team members, and thus to improve the quality of care" (Güell et al. 2013, p. 529; the care network is depicted by Soriani and Desnuelle 2017, p. 289).

This setting calls for digital platforms to optimize care coordination and research, as they can facilitate exchanges between these multiple stakeholders involved in the care for ALS patients and add to the current knowledge about the disease by collecting and analysing patient data.

\section{Data collection and analysis}

Data collection To capture the perspective of multiple stakeholders and to control for bias, we used several data sources for triangulation purposes (e.g., Lincoln and Guba 1985; Yin 2018) (see Table 1). First, we have collected primary interview data from APST $(n=10)$. Building on an informal talk with one founder in January 2019, the first author conducted two confirmatory interviews with the founders (first with one founding partner and a second with both founders). Applying snowball sampling, the founders provided access to other employees within the platform firm, including the care research manager, allowing us to gain deeper insight into the firm's internal business logic and processes. Further, we have attended an APST supplier workshop in November 2019 and interviewed suppliers to complement the platform owners' perspectives $(n=9)$. The full-day event also allowed us to administer a survey and to collect structured responses from $n=14$ individuals. As a third perspective, we gathered formal interview data from patients and patient representatives. Patient organizations were contacted individually and interviewed in April $2020(n=6)$, with patient interviews $(n=3)$ following in November 2020. Since one interview partner was not able to speak anymore due to his illness, a written conversation was substituted in place of our verbal interview. These viewpoints helped us to relate the platform and supplier responses with concrete patient needs and challenges. Further secondary and archival documents were collected to supplement, complete, and expand the analysis. One author attended two presentations from APST and obtained the presented slides afterwards. APST provided additional internal documents (e.g., outlining its governance structure and the content of current research projects). Moreover, we collected the totality of news articles and Facebook posts (including uploaded videos) of APST, as well as academic articles covering APST published in general outlets and in media coverage since its foundation in 2011 up until July 2020.
Data analysis We analyzed our data following an abductive approach (Alvesson and Kärreman 2007; Locke et al. 2008), posing theoretical questions based on data and constantly cycling between data and theory. After storing our data in a case study database (Yin 2018) using the software MAXQDA, we conducted a qualitative content analysis (e.g., Mayring 2000; Schreier 2014) by systematically assigning "successive parts or the material to the categories of a coding frame" (Schreier 2014, p. 170). We were able to reduce our data and thus focus on selected meanings related to our research question. Coding started in a deductive manner. Existing frameworks on business model innovation and configurations (e.g., Foss and Saebi 2018; Teece 2010) provided starting points for coding the business model configuration of the platform. We began by coding the different activities of the platform, as well as the value created for different stakeholders, such as the platform provider, patients, physicians, other care providers, and actors interested in contract research. The coded value includes value regarding patient-related outcomes such as quality of life, value related to results of clinical and health service research, and value related to efficiency (e.g. coordination of care, increased market share). Moreover, we coded further components of the business model to reveal who captures value (including revenue streams) and how value is delivered. In addition to deductive coding, new inductive codes emerged during data analysis. For instance, an "involvement in tracking disease status and quality of life" amongst patients, emerged as a theme in our analysis. Our coding was therefore both concept- and data-driven. In a further step of data analysis, we linked our codes to three phases of platform development that display the enactment of different business model facets. With the help of this axial coding (Strauss and Corbin 1990), we are able to reconstruct the development of APST's business model over time. Three members of the research team coded data and all members of the team held regular discussion meetings on emergent findings. During each step of data analysis, we compared coding and emerging interpretations, such as the platform's logics of patient-centric value creation. By following this approach of data analysis, we were able to reconstruct the platform's business model development.

\section{Findings}

\section{Business model development}

Our longitudinal analysis of APST identified two main business models, namely: a care coordination model (business model 1) and a care research model (business model 2). A further building block that was subsequently introduced to extend both business models was active- and direct patientinvolvement (as an 'extending business model pattern'). In their structure, these business models mirror important aspects 
Table 1 Data sources

\begin{tabular}{|c|c|c|c|}
\hline \# & Source, role, and description & Period & Quantity \\
\hline \multicolumn{3}{|c|}{ A - Primary interview data from platform owner firm (APST) } & $n=10$ \\
\hline 1 & Formal confirmatory interview with founders (\#1.1-1.2) & March / July 2019 & 2 \\
\hline 2 & Formal confirmatory interview care research manager $(\# 2)$ & July 2020 & 1 \\
\hline 3 & Formal interview with app and IT support manager & November 2020 & 1 \\
\hline 4 & Informal talk with founders (\#3) & January 2019 & 1 \\
\hline 5 & Informal talks with care research manager (\#4.1-4.2) & July / Sept. 2019 & 2 \\
\hline 6 & Informal talks with other employees at supplier workshop (e.g., case management) (\#5.1-5.3) & November 2019 & 3 \\
\hline \multicolumn{3}{|c|}{ B - Primary interview and observational data from suppliers } & $n=9$ \\
\hline 7 & Informal interviews at supplier workshop $(\# 7.1, \ldots, 7.5)$ & November 2019 & 5 \\
\hline 8 & Formal interviews with suppliers (e.g., medical supply stores, assistive device firms) (\#8.1 ... 8.4) & April 2020 & 4 \\
\hline 9 & Attendance of / observation at supplier workshop (incl. Field notes, gathered materials) (\#9) & November 2019 & Full 1-day workshop \\
\hline 10 & Short survey administered at supplier workshop (\#10) & November 2019 & 14 valid responses \\
\hline \multicolumn{3}{|c|}{$\mathrm{C}$ - Primary interview data from patients and patient representatives } & $n=9$ \\
\hline 11 & Formal interviews with patient representatives (\#11.1-11.5) & April 2020 & 5 \\
\hline 12 & Written conversation with patient representative (\#12) & April 2020 & 1 \\
\hline 13 & Formal interviews with ALS patients (\#13.1-13.3) & November 2020 & 3 \\
\hline \multicolumn{3}{|c|}{ D - Internal data from platform } & $n=8$ \\
\hline 14 & $\begin{array}{l}\text { Internal documents by APST (e.g., internal platform governance concept (2018), general terms } \\
\text { and conditions for suppliers, patients, medical partners; presentation to students (2019), } \\
\text { neurology congress presentation (2019), registry study protocol (2020), data security concept (2020)) }\end{array}$ & 2018-2020 & 8 \\
\hline \multicolumn{3}{|c|}{ E - Secondary and archival documents } & 220 sources \\
\hline 15 & News articles & 2012-2018 & 40 \\
\hline 16 & Facebook posts by APST & $2011-2020$ & 163 \\
\hline 17 & Videos uploaded by APST & 2013-2014 & 5 \\
\hline 18 & Scientific publications on health services research of the platform & 2013-2018 & 7 \\
\hline 19 & Media coverage (e.g., Spiegel, Ärzteblatt) & $2011-2015$ & 5 \\
\hline
\end{tabular}

of value-based healthcare (VBHC) and provide rationales for the platform's strategic extension of its scope of activities. Table 2 maps APST business models (and patterns) to the logic of patient value-creation according to Porter's concept of value-based healthcare (VBHC). Appendix 1 details these patterns, shows our coding structure, and gives representative quotes from the qualitative data.

\section{Business Model 1. Coordination of Care}

In 2011 APST was designed as a multi-sided platform, linking patients to their doctors and care providers, as well as to ATD vendors and then gradually extending into therapeutic service management (e.g., physical therapy, speech therapy, occupational therapy), pharmacies (medications), nutritional therapy, and nursing care services (see Fig. 1). Consequently, the traditional process (patient - doctor - insurance - care or equipment provider) is transformed and APST has been established as an intermediary between patients (or prescribing doctors) and service (care) providers. Care providers pay a platform license fee per patient, while platform use is free for doctors and patients. Even though the platform supports direct exchanges between care providers and patients (e.g. provision of care and care devices), it aims to build on existing relationships between patients and care providers, which limits crossside positive network effects. Further, instead of emphasizing or presuming self-service by patients - the typical pattern employed by commercial digital platforms-the APST platform engages extensively in care coordination and patient support (case management). The digitization of patient-, care- and transaction data management is a key contribution of the platform. Concurrently, this is a precondition to improve efficiency for the types of personnel-intensive coordination that is required for ALS patients (on the state of integrated care in Germany see: e.g., Amelung et al. 2012; Brandhorst et al. 2017).

The APST platform portal released its first version in 2011 with a focus on ATDs, which over time, was rolled out across Germany. Their scope, however, was expanded beyond ATDs, quite early on (directly after 2011) to include a module for therapeutic service management, which has so far been rolled out only in the ALS centres network at the Charite Universitätsmedizin Berlin (Charité - University Hospital). In 2012, a nursing care management module went live (e.g., 
Table 2 Mapping of the logic of patient value creation to APST business model

\begin{tabular}{|c|c|c|}
\hline Business model & APST focus & Primary area of VBHC \\
\hline Coordination of Care & $\begin{array}{l}\text {-Effectively managing resource-intensive, patient-centric care (and cases: fast, } \\
\text { linking patients and care providers, individualized care). } \\
\text {-Facilitating transactions and efficient administrative processing (information } \\
\text { management, prescription processing, approval of ATD provisioning, insurance } \\
\text { coverage/ reimbursement). } \\
\text {-Storing and making accessible information and communication, improving the } \\
\text { efficiency of care coordination. }\end{array}$ & $\begin{array}{l}\text { Efficiency improvements, quality of } \\
\text { care }\end{array}$ \\
\hline Care Research & $\begin{array}{l}\text {-Collecting feedback and surveys, enabling feedback-based quality improvements } \\
\text { of the platform services. } \\
\text {-Real world evidence-based research (as there is no known cure) to improve the } \\
\text { alignment of progressive diseases and related care needs on the one side and care } \\
\text { provision on the other, drawing also on PROMs and PREMs (e.g., Funke et al. } \\
\text { 2018, 2015). } \\
\text {-Performing research trials on medical outcomes and patient related outcomes } \\
\text { (PRO): Extended data base allowing for improved research outcomes, including } \\
\text { studies that included (e.g., Meyer et al. 2020; Meyer et al. 2019), or centred on } \\
\text { PROMs (e.g., Meyer et al. 2018). } \\
\text {-Soliciting a large, representative sample as the basis for evidence-based research, } \\
\text { which includes the ability to document the effectiveness of care (as a prerequisite } \\
\text { for insurance coverage). } \\
\text {-Platform-based care processes facilitate comprehensive data capturing (patient, } \\
\text { care, transaction data, patient feedback) as a basis for extended care research } \\
\text { (scale and scope of available data are unprecedented, ongoing extension of data } \\
\text { capture). } \\
\text {-Doing contract research. }\end{array}$ & $\begin{array}{l}\text { Medical and patient-related outcome } \\
\text { improvements, quality of care }\end{array}$ \\
\hline $\begin{array}{l}\text { Extension: Active and } \\
\text { direct patient } \\
\text { involvement }\end{array}$ & $\begin{array}{l}\text {-Involving patients in tracking disease status and quality of life for (1) monitoring } \\
\text { the progression of the disease in order to facilitate the provision of care, as well as } \\
\text { giving feedback, and (2) participation in data collection for research, giving } \\
\text { consent to data use. } \\
\text {-Providing prospective needs-based care: prediction of emerging care needs, so that } \\
\text { e.g. ATDs are available when needed, capturing of patients' bio markers for early } \\
\text { on diagnosis and research. } \\
\text {-Through the ALS App, patients can submit orders for care material or medication. } \\
\text {-Patients' relative or designated caretakers are registered on the platform and can act } \\
\text { as facilitator for the patient, if and when needed. They may also set-up their own } \\
\text { account on the ALS App. }\end{array}$ & $\begin{array}{l}\text { Patient-related outcome } \\
\text { improvements, access to and } \\
\text { quality of care }\end{array}$ \\
\hline
\end{tabular}

support for daily activities such as washing, wound and pain care), which, however, is not yet used with the same intensity as the ATD module, and which is currently limited to the Berlin area as well. It took account of a high degree of complexity in nursing care, since dynamic forms of care are implemented in the spectrum of outpatient, day-care or inpatient care during ALS disease progression (Meyer et al. 2013). In 2013, a module for medication management went live, which, to this day, is realized via connecting online pharmacies and is currently also limited to the Berlin area. As the founder noted in a workshop $\left(\# 9^{1}\right)$, "In the field of pharmacotherapy, prescriptions are already put online as PDF files at APST, at the time of application and before assessment by the health insurance." This also strengthened the platform's core as a care management and transaction platform.

The care coordination business model is an instantiation of the multi-sided platform business model. However, in contrast to a pure focus on facilitating efficient transactions, that is, process facilitation and automation, APST has emphasized care management, implemented as individualized, patientcentric case management (i.e. it takes a very active and personnel-intensive intermediary role). In this way, it is an interesting outlier compared to other pure transaction platforms. The kernel of the platform's service is to build on and extend existing patient-supplier relations. In a federal health-care system, in which digital patient records have not yet become the norm, the platform itself has become a significant data repository, enabling storage of and access to, information and communication. Each patient's electronic health record, and the additional medical and technical information required for the procurement and provision of ATD, are documented on the APST platform. Digitized administrative information (e.g. prescription refills) are used during procurement processes. The platform began with 200 registered users

\footnotetext{
${ }^{1}$ References refer to sources listed in Table 1.
} 
Fig. 1 APST's care coordination model

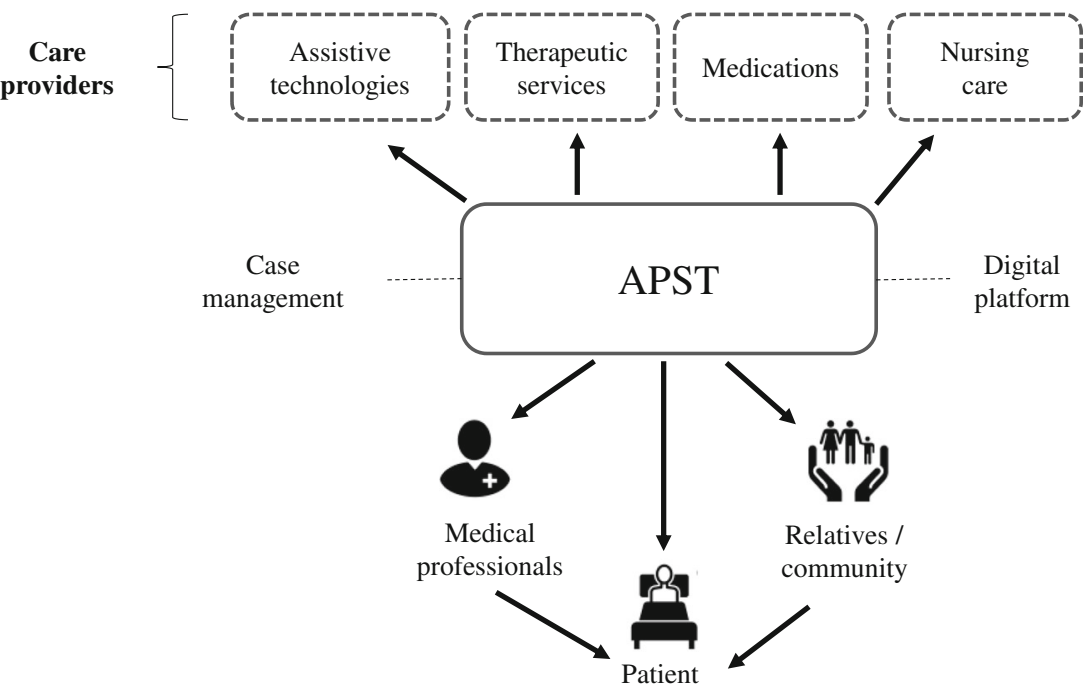

of almost exclusively ALS patients. Within a period of 9.5 years, the user base exceeded 12,000 registered patients. Approximately $50 \%$ of registered patients suffer from ALS, with almost all other users coming from a similar background, of a different complex neurological disease, such as multiple sclerosis, stroke, Parkinson's disease or muscle diseases, with a current amount (2020) of approximately 3000 active ALS patients on the platform. Initially, most patients were referred to APST by their GPs or specialist doctors, though the ALS App has recently motivated new patients to register on the platform. Generally, access to the platform is free and inclusive for all groups of patients. However, health literacy, digital health literacy, and environmental factors (e.g., who gets to know about it) may limit access, which is, however, less likely than in other settings given the high proportion of the ALS population already enrolled on the platform.

Further, the number of providers on the platform grew consistently, as was demonstrated in a 2017 survey: 1273 providers took part in the APST network, up from 1061 providers in 2015. Similarly, the number of medical partners has significantly increased. Initially the ALS centre at the Charite had focused on coordinating ATD supply to their patients $(67 \%$ or 941 ATDs were distributed between June 2011 and October 2014; Funke et al. 2015). While APST started with four ALS centres, today it includes 16 ALS centres throughout Germany. 155 medical doctors took part in patient care using APST in 2014, and the number is increasing. These scaling dynamics have helped to create a crucial patient sample for care research (beyond transactional value).

\section{Business Model 2. The Care Research Model}

The initial design of APST was developed as part of a funded research project. In parallel to the development of the platform, the research model took shape, and as the platform operation created both a unique patient sample and an increasing pool of data, the model extended.

The care research business model is an instantiation of a data-driven / datafication business model (Guggenberger et al. 2020; Kelly and Noonan 2017). It uses data as its basis for examining care processes and for enabling different forms of care research. At the same time, APST has been successfully generating revenue for the platform provider. APST combines different modes of mostly collaborative research: patient- and platform-centric care research, vendor care research, neurological research (including development of algorithms), and public health research. Types of data include: the electronic patient record saved in APST (as part of the "information and communication" activity), transaction data such as ATD orders and prescriptions (from the "transaction platform" activity"), (structured) patient care feedback (from "patient feedback and surveys" activity), care research data (e.g., surveys from "evidence-based care" and "research trial" activities), contract research data (from the activity with the same name), and increasingly patient digital traces on the platform (such as patient care orders, clickstream data), patient digital biomarkers (such as speech and breathing samples collected via the App), as well as stratification and scoring data (emerging in the context of the "prospective, needs-based care activity"), such as the ALS functional rating score. The patient-centric and platform-centric care research model focus mainly on improving quality of care and care coordination as well as on patient-facing relevant platform activities. This model is cross-subsided from the care coordination model, as well as third-party funding (e.g., federal ministries of research and of health). The vendor contract research model focuses on the improvement of quality with specific devices and technologies. Public health research has been focused on issues such as cycle time for products or costs, which are relevant for regulators / policy makers, and health insurance providers, among others. Such research is often funded by 
third-party funding organizations and benefits the co-founders who are themselves professors at a major university hospital.

APST increasingly emphasized quality management (quality assurance) by regularly and consistently polling patients in order capture their perception regarding available services and product quality (which could then be provided as feedback to the service and equipment providers). This creates a general message to the patients that their satisfaction matters and that they are taken as judges of the provided quality and that the platform would respond appropriately in cases of their continued dissatisfaction. It also creates a signal to the providers that they are monitored for the quality of their services, but also that they will get systematic feedback, which is captured in line with academic standards about the perception of services in relation to the condition of the patients. The first category in this regard is patient feedback and surveys, which began in 2014 with a survey module being integrated into the platform. Here, patient information, transaction data and systematically structured patient feedback (regarding the quality of services and equipment) have been combined. This allowed patients to rate ATDs, therapeutic products, medications, delivered care, as well as providers, medical partners, and the platform itself. It enabled constant feedback and learning, and presented an important step in the direction of an information platform.

Another important activity of the platform became evidence-based health care research, allowing for improvements of the quality of provision of care and ATDs to ALS patients. Based on the data collected on the platform-including patientreported outcomes collected for various research studies-and its access to a unique patient community, the platform is used as a research infrastructure. Such an infrastructure is comprised of: (1) health services research and (2) ALS and neurology-related medical and pharmaceutical research in order to study the overall quality of care provision (e.g., a comparative study of the provision of ATD across four ALS centres, which showed that only $64 \%$ of indicated ATDs reached the patients) (Funke et al. 2015, p. 1010).

Given that APST supports about $50 \%$ of the German ALS population, it has access to the largest ALS in Germany, which can be used for multiple studies. Among which include an ALS registry study, which analyses results in the patient population.

The care research manager noted in an interview (\#2) (in relation to the role research plays in the platform) that, "We use [the platform] (...) in the context of many research projects... we also have research projects that are financed by the G-BA [governing body in German healthcare], i.e. Innofonds [Innovation Funds] projects, that all run partly on our platform." Studies that have been conducted within the context of the APST ALS registry include both ATDs and therapeutic services, such as the effectiveness of care for ALS patients who have received care using a robotic arm or a mechanical cough assistant. It also concerns research trials on (medical) outcomes, striving to improve the effectiveness of pharmaceutical products (e.g. pharmaceutical interventions for the treatment of difficulty in swallowing or for spasticity). Patients have each separately agreed to the use of their data for care management and the use of their data for care service improvement, as well as for participation in the registry study and the individual studies within the registry study. These individualized studies also include contract research for ATD and other service providers, such as when there was "a Swedish wheelchair manufacturer wanting to know the needs of the served population" (Founder in interview \#1.2). This became an additional revenue source for the platform.

\section{Ongoing business model innovation: active and direct patient involvement}

Initially, as noted by a platform co-founder (in \#1.2), "APST functioned mostly as a business-to-business platform between specialized physicians and providers. What is still problematic is to integrate patients in the first place and to match them to specialized physicians." Recently, the platform has transitioned towards more direct and active involvement of the patients, either through data collection or transactions driven by the patients themselves. Instruments towards this purpose can consist of, namely: continuously tracked surveys and assessment procedures to assess the quality of life of the patients (e.g., an ALS functional rating score (ALS-FRS)), a patient-reported outcome measure, as well as extended feedback and assessment mechanisms. The means towards such an implementation include a newly developed smartphone app for patients, which has helped foster patient involvement in tracking disease status and quality of life.

The platform also integrated additional feedback and care management functions, such as the possibility for a patient to signal his/her upcoming care needs through the app (e.g., need for new ATDs). As the care research manager (\#2) noted, "While ALS Functional Score has been used before, in the context of individual scientific studies, digital solutions are trying to improve the dimension of quality of life - and wellbeing - and functionality - of patients now that there is the possibility for ALS patients to directly report their needs". The stated vision is of a prospective needs-based care, using individualized risk stratification and matching between patients and medical providers and ATD/therapeutic providers. As one supplier (in \#9) had envisioned, "Start the care process before the patient identifies his or her needs." In order to achieve this, sensor and movement data of patients are being increasingly utilized. Analogous to the "Internet of Things," using the ever increasingly available sensor and tracking data to match between patients and medical providers becomes a focus of attention ("Internet of Care", \#14). 
This shift is supposed to affect the current business model in several ways. The organizing vision regarding the care coordination model becomes more detailed and fine-grained. New secondary and tertiary uses emerge, resulting in a stronger integration between primary, secondary, and tertiary operations of the platform, with an emphasized research component. In terms of key functionality, new research uses emerge, including: both the patient sensor data and more detailed tracking. This enables more individualized diagnoses based on a large sample. Structurewise, the shift enables new networks, including monetizing data and conducting research, as a contract research organization. It also strengthens the existing partnerships, as partners receive better and more individualized feedback. In terms of modes of interaction on the transaction side, algorithmic analyses of patient data come to the fore. Research-wise, survey data has become more individualized and offers real-time prognostic values. Finally, in terms of modes of appropriation, algorithmic assessments of patient needs are prioritized, as are the benefits of (sensor) monitoring and tracking, contributing to an evidencebased discourse about healthcare quality and outcomes.

\section{Symbiotic design of the care coordination and care research model}

In effect, APST combines two distinct, yet related business models: the (1) coordination of care and (2) care research. The two models represent different logics, coordination and transaction versus data collection, analysis, and dissemination of results. As Fig. 2 shows, the care research model can be further decomposed into the following: a patient- and platform-centric model, a vendor care research model, and a public health research model.

Both business models have different yet overlapping stakeholders (or business actors in Timmer's (1998) terminology), deriving different benefits from their relation to APST's two models (see Table 3).

Generally, we found that the platform's two main business models have been well aligned, enabling patient value creation and at the same time sustainable value capture for the platform operator. Most of the activities described are symbiotic in the sense that model (1) is the key source for research data (in model (2)): "This is due to the fact that we are convinced [...] that hybrid structures are essential" (Founder in \#3). Additionally, "Data generated in the context of care management is used for a systematic analysis of care on the basis of informed patient consent. This results in a 'dual effect': The digitization of care data on the APST Internet portal serves directly to coordinate care and at the same time research into care through the evaluation of 'routine' data (real world evidence)" (Founder of the platform in \#14). Feedback on care provision, which is part of the platform's quality management, is also research input. The platform uses experience sampling, i.e. patients reporting on their own condition and progression of disease, such that "There is now also the possibility for
Fig. 2 Mapping of data codes to business models

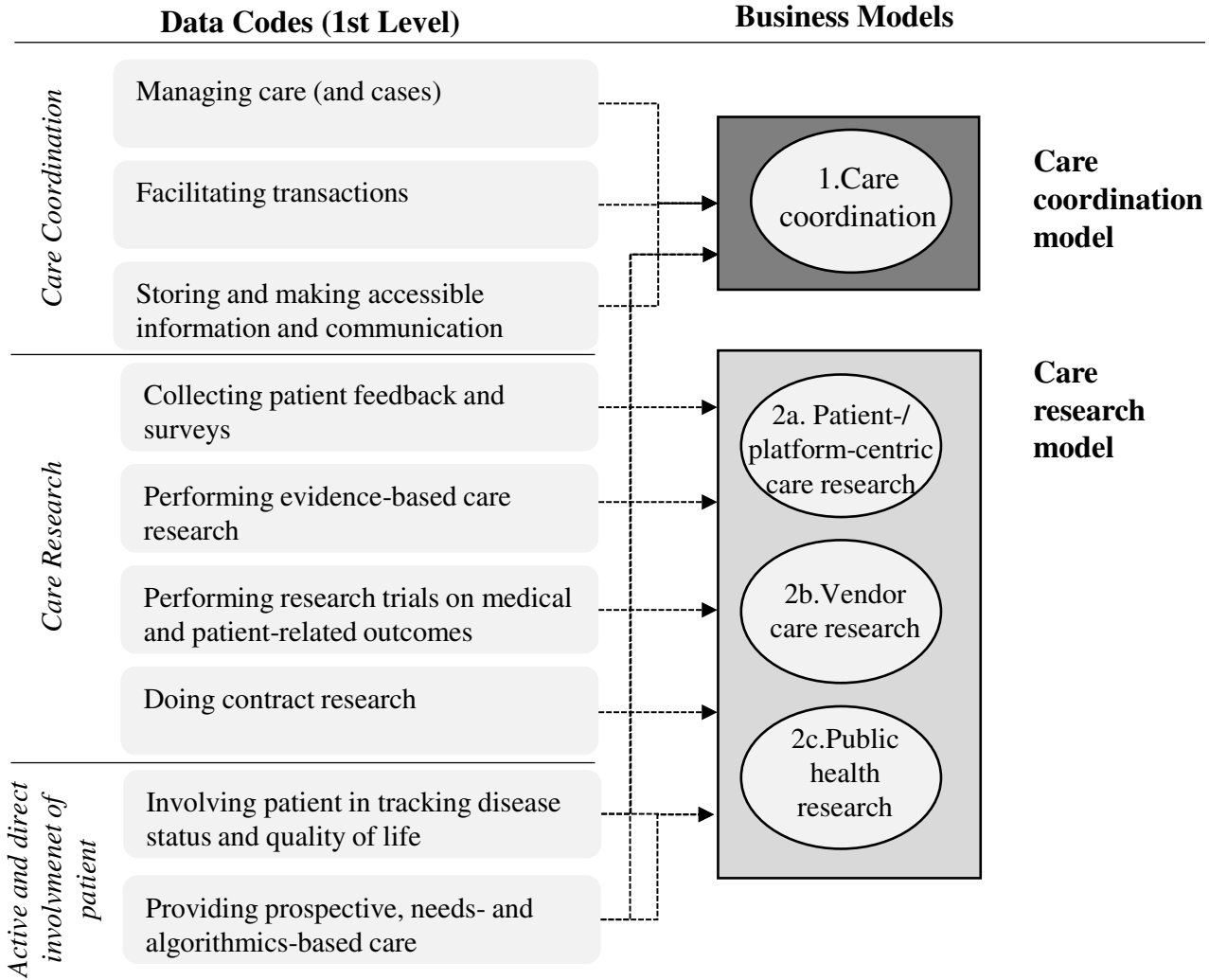


Table 3 APST stakeholders and their benefits related to the two business models

\begin{tabular}{ll}
\hline Primary stakeholders & Benefits, values
\end{tabular}

Patients (as well as relatives and community)

Medical professionals (e.g., GPs, specialists, ALS centres)

Health care providers

Secondary Stakeholders (not in Fig. 1)

Commercial research sponsors

Health insurance providers

Recipients of research results (current and future patients, research community, health care regulator)
(1) Effective care coordination, the related transactions, as well as patient health information management.

(2) Benefit of research findings, e.g. improved diagnostics.

$(1+2)$ Active involvement (co-production) of platform operation via app use and participation in research.

(1) Improved care for their patients, partial outsourcing of record keeping (patient health information management).

(1) Improved coordination of health care provision, patient health information management.

(2) Reports of patient feedback on care and devices.

(2) Contract research management and access to large and representative patient sample.

(1) Care coordination support.

(2) Evidence-based research findings as a basis for planning and decision making.

(2) Evidence-based research findings as basis for planning and decision-making.

${ }^{1} \ldots$ benefit derived from care coordination model, ${ }^{2} \ldots$ benefit derived from care research model

ALS patients to report their needs directly. [...] which is evaluated by the patient via the app, [it] is also displayed graphically in the outpatient partner account" (Platform operator). The patients utilizing the platform form a large and natural sample for research-related data collection since "This patient cohort is absolutely representative for all other cohorts" (Founder in \#1.2), for over time a substantial data pool, with various, complementary data, has been generated, which provides a treasure trove for ongoing and future research.

Diverging strategies have been pursued with respect to scaling. The transaction platform activity focuses on scale while case/care management involves considerable human labour, in turn slowing down or even preventing national scaling due to complex networks in each of the platform's supply sides (i.e., ATDs, therapeutic devices, medications, and nursing care services). We observed different levels of regional scaling for each of these sides, ranging from national (in regard to ATD distribution) to local (in the Berlin area for therapeutic devices and nursing care services), while in the case of medications, the collaboration with online pharmacies mitigated the problem. Another aspect of interference was contract research and many of the platform's care-coordination and patient-facing activities. Although these were complementary from the data side as described earlier, the platform was very sensitive towards explaining to the patient how their data is used and how it could be used in further studies, including contract research. While there is a potential tension, it did not figure prominently in the data given that the platform had taken deliberate steps to mitigate the problem, as clear and understandable data usage policies with separate checkboxes for different types of studies, legal counselling and concepts for data security, as well as an educative approach to explain to patients the reason for necessity of this activity.

An empirically appropriate characterization of the patterns incorporated in APST would be the symbiotic combination of the coordination and transaction platform, as well as the data collection and information management platform (together: care coordination model), and a research platform, whereby the two models complement, benefit and rely on each other. Figure 3 summarizes the mutual reinforcement of the care coordination and the care research model. Initially, care research led to the establishment of APST. Thereafter leading

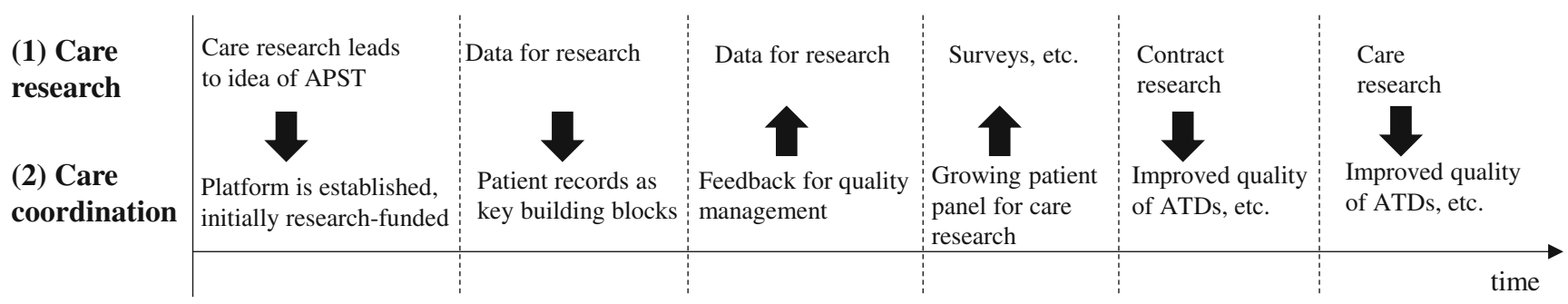

Fig. 3 Configuring of data codes into two main business models 
to patient records and other data enabled research, which became further complemented over time, by subsequently informing and transforming the quality of care and enabling patient-centric improvements.

\section{Discussion}

This paper aimed to examine how multi-sided health platforms enact business models to create value for patients and foster care research in a viable manner. We have provided a detailed analysis of a specialized health platform, which reflects the contingencies of ALS care in Germany, and reconstructed the development and interaction of its business model over time. For this purpose, we have built on value-based care (Porter 2008; Porter and Teisberg 2006) and business model literature (e.g., Remane et al. 2017; Sabatier et al. 2010; Teece 2010). Our analysis has revealed two business models that had been integrated and extended by the platform provider. The first model, which we describe as "care coordination model", started with individualized case management to address immediate patient needs, as well as supporting the care management by an MSP. This allowed to mobilize economies of scale and improve transaction efficiencies, including building an information platform to document information about the platform participants (from patient care records to technical specifications of ATDs). Building on and extending this pool of data into a treasure trove for research, the second business model, which we call "care research model", helped to initiate several feedback loops for learning across multiple stakeholders, to reach research goals, and to increase the quality of care services. The research findings generated by the platform contribute to care research for the benefits of the patients and the platform, the vendors and public health. Both business models were subsequently extended by business model innovation towards stronger and more active patient involvement, using digital biomarkers and sensor data for better research and more individualized matching of patients and medical research partners.

Our analysis contributes to three debates: (1) The notion of business model patterns and the relationship between different business models, (2) the potentially disruptive role of MSPs, and (3) how to mitigate the conflict of interest between patients' privacy and the interest and potential benefit of patient data driven research. Subsequently, we illustrate limitations of our analysis and resulting avenues for further research.

\section{Business model patterns and relationship between business models}

Business model innovation is largely based on the imitation, adaptation and re-combination of existing business model patterns (Gassmann et al. 2014; Remane et al. 2017). Such patterns describe facets or building blocks of business models, e.g. pricing models, but they do not describe business models comprehensively. The founders of APST have mentioned popular examples of MSPs (Uber, AirBnB) as references for their platform. Despite structural similarities of linking different groups of platform users, namely patients and care providers, the specific design and operation of the platform are quite distinct from the mainstream MSP. (1) Despite digitalization of data flows and transaction, APST aims for individualized case management in contrast to a standardization of transactions that is common for other MSPs in health care and beyond. While this puts constraints on the scalability of the platform business model, it allows to support patients with a rare and complex neurological disease in terms of both care and research. (2) APST coordinates a quite heterogeneous group of care service providers what is uncomment for MSPs that often rely on few homogenous segments. (3) APST reinforces and complements existing relationships between patients and care providers, contrary to other platforms that usually broker new and temporary relationships. (4) Overall APST plays an extensive role, not only as platform provider but as research organization, research coordinator and liaison to external stakeholders (insurance companies, health regulators).

Most mature, diversified enterprises can be depicted not as just one, but as an ensemble of several business models (see also Sabatier et al. 2010). Along this line, we have analytically divided the APST business model into two separate business models that follow distinct logics and could hypothetically be run independently: the care coordination and the research model. APST's recent movement towards a patient-centric model could also be depicted and analysed as a yet another business model to carve out the specific constellations of actors involved in the generation of value and the revenue model.

Yet the emphasis of our analysis was not the separation but the co-evolution and the dynamic alignment of both models under the overarching business model of APST (as depicted in Fig. 3). Improving patient care is the overarching goal, which is generated in different, yet closely coupled ways. Research yields ongoing reflection and is a driver for continuous improvement for APST.

\section{APST as disruptor in the healthcare market?}

The development of MSPs in particular are closely linked to the notion of disruptive innovation, i.e. successfully competing with incumbents through novel uses of technology and a rethinking of customer value (Hwang and Christensen 2008; Kazan 2018). APST's care coordination model could be, on the one hand, perceived as disruptive for the German health system: APST is de facto addressing coordination 
inefficiencies by intermediating the relationship between care providers and patients - a role not foreseen in the German health systems in terms of legislation and budgeting. Yet, APST has positioned itself not as a disruptor, rather as complementary, cooperative, supportive, and symbiotic in relation to the main stakeholders (cf. Table 1). Next to linking different stakeholders (cf. Fig. 1), APST also facilitates interprofessional coordination and collaboration among specialized care providers. We would qualify APST as complex business model innovation, architectural in scope and new to the industry (Foss and Saebi 2018, p. 14), which nurtures cooperation and value-based competition (Porter and Teisberg 2006). It aims at using its research findings to initiate reform of the health care system (Porter and Guth 2012), specifically the regulatory framework for care of neurological diseases (founder \#8). The design and the development of the platform is an encouraging example of how digital care models aiming for integration can be developed and improved. This especially applies to a country such as Germany, where intersectoral care as well as digitalization of health care (e.g., no nationwide digital health infrastructure exists) is still lacking (e.g., Amelung et al. 2012; Brandhorst et al. 2017).

\section{Datafication and value extraction}

The growing datafication, i.e. the transformation of academic disciplines and professions based on the extensive collection and analysis of (big) data, has raised profound concerns about long-term societal impacts (Newell and Marabelli 2015). Kelly and Noonan (2017) provide empirical evidence from a study of health services how datafication yield valuable insights if it is used in a dialogic, sensemaking manner, which encourages to engage with data in a critical way. We see APST's approach in line with a dialogic approach as multiple data source and data collection methods are combined and the research findings are applied and contextualized in care processes.

Data-driven business models, which collect and monetize user data in an opaque manner and without the users' consent, are increasingly critically perceived as value extracting (Mazzucato 2019), exploitative (Zuboff 2019) and violating users' rights (Mai 2016) rather than generating value for customers. Patient information and health data are particularly sensitive and require even higher standards of privacy protection and user consent.

Both APST's business models are data-driven, therefore APST has put emphasis on data protection. Its data protection rules demonstrate a heightened sensitivity to the strict privacy regulations applying to patient data. The extensive data pool is built on the principles of fair and transparent data sharing by the patients, who are asked for informed consent and can decide in a differentiated manner if and how much data they are willing to share. Importantly, the patient data are not used for advertising (revenue) but only for research and feedback to care providers, the patients are directly and indirectly benefiting from sharing their data and the subsequent research results.

In sum, the complex business model enacted by APST is not a classical business model, aimed at maximizing revenue, but a medical care and research model. Both models are well aligned, tightly integrated and provide the basis for the ongoing development of the platform. Thereby, it became possible to create value for a patient population, while at the same time generating revenue streams to do so.

\section{Boundary conditions}

APST is a single case study embedded in the unique context of the German health system. We have demonstrated the merits of an in depth, dynamic, multi-stakeholder analysis (cf. also Flyvbjerg 2006), addressing multiple levels of analysis (cf. Haddad et al. 2015). The research design affords to understand the contingencies of longitudinal business model development targeted at ALS care, which puts any healthcare system to its limits: Providing the appropriate care in a timely manner for patients with a quickly deteriorating condition, who need a highly diverse spectrum of care and assistance, is a daunting challenge. We add to the existing studies on health care platforms, which have typically focussed on the United States (blinded reference; Mandel et al. 2016; Yaraghi et al. 2015) and the Scandinavian countries (Aanestad et al. 2017; Aanestad and Jensen 2011; Vassilakopoulou et al. 2017), which have unique regulatory and social policy conditions. However, comparative studies of other health platforms that address rare diseases in different national health systems would clearly complement our study. Our focus on a platform addressing a rare disease is a boundary condition of this study that affects transferability of insights to more widespread diseases (e.g. diabetes, coronary diseases, and different forms of cancer). As part of future work, an extension of patient interviews is desirable. Moreover, we can assume that patient access to such health platforms may be limited by social determinants of health (Artiga and Hinton 2018), including the availability of digital devices and digital health literacy. Future studies could explore this issue in more detail.

\section{Conclusion}

Our study offers two main contributions. The first is towards research on business model development in the context of MSPs. By reconstructing the evolution of the first health platform that coordinates complex care processes for patients suffering from complex neurological diseases, we are not only able to provide a detailed account of platform growth but also 
the ongoing refinement of the platform model including development paths for the future. Our research thus extends previous accounts of MSPs that address more widespread and chronic conditions (blinded reference; Otto and Jarke 2019; Yaraghi et al. 2015). The longitudinal analysis provides insights into a rich case of a platform that enables individualized patient-centric coordination of care and facilitates interprofessional cooperation. Moreover, the platform enables evidenced-based research on the provision of ALS care, ALS medication and ATD, as well as algorithmic analysis of ALS patient data to improve diagnosis, prediction, and care. The case also sheds light on the co-evolution of two distinct, yet closely aligned business models, which enabled the growth and scalability of the platform. Thereby, it also shows how platform providers are able to manage tensions (Mini and Widjaja 2019) in the context of such complex business models.

Our second contribution is to the concept of value-based health care (Porter 2008; Porter and Teisberg 2006), as we show how a platform's use of technology and economic principles can improve the quality of care for complex diseases, requiring comprehensive care. The case analysis illustrates how an MSP can extend patient value creation in three steps: (1) efficient and effective coordination of the provision of care and the underlying transactions during the first phase, (2) managing the quality of care and medical outcomes, and (3) direct patient involvement through App-based monitoring and transaction support. Building on the expansion of the care model, the research model has been extended: the care model provides a growing and representative data pool of patient and care data, which is complemented by dedicated research projects, some of which have been contract research, and included additional efforts of data collection (surveys, patient experience sampling, etc.).

In effect, this amounts to a complex business model innovation (Foss and Saebi 2018) that integrates care coordination and care research. By taking a multiple stakeholder perspective, the platform design and development shows not only how platform providers can achieve an incentive compatible stakeholder configuration, but also how they can facilitate a dynamic of ongoing learning and improvement across and between different stakeholders without violating the patients' rights and interests.

From a practical perspective, we show by highlighting the example of APST how and under which conditions the sustainability of multiple business models in health care is possible and at the same time necessary to generate value for patients with complex neurological diseases. This case is a prime example for how a multi-sided platform model can be used to achieve and coordinate care in a better way. It also demonstrates the unique opportunities of research platforms as an additional organizing vision for health care platforms. In its configuration, it exemplifies a European model of patientcentric health care platforms. While APST mitigates some of the shortcomings of the current ALS care system in Germany, it also sets an example of how care could be organized within the organizational and regulatory structures of public health care.

\section{Appendix}

Table 4 Data supporting different activities underlying the platform's business model

\begin{tabular}{ll}
\hline Data code (1st level) & Representative quotations \\
\hline $\begin{array}{l}\text { Business model 1: coordination of care } \\
\text { Managing care (and cases) }\end{array}$ & "[It's a] network, which intensively cares for my disease." (Patient \#13.2) \\
"Even though the initial experience was negative: after six weeks where not a single speech therapist had responded, \\
the platform is a godsend for me and my wife. ATD providers have responded within days and replenishments for \\
medication arrived ahead of schedule." (Patient \#13.1) \\
"There is also a contact person, especially for the patients, and that is fine. That is important and that is good." \\
(Supplier \#8.1) \\
"And these modules are rolled out differently at the individual outpatient clinics throughout Germany, i.e. the \\
assistive devices module is available throughout Germany, which means that an assistive device provider usually \\
has a nationwide stance and can provide care for patients throughout Germany." (Founder \#1.2) \\
"The focal point for APST lies on complex conditions with complex medical requirements [...] this means that they \\
need sophisticated devices, not just a rollator or not just a simple wheelchair or walking stick, but actually also an \\
electric wheelchair and a communication aid.” (Founder \#1.2) \\
"The Berlin-based care portal 'APST', [...] provides support in facilitating the supply of suitable aids, remedies, \\
medication and care, provided a valuable aid." (Media article in source \#15) \\
"You must imagine that APST is practically a major transaction hub." (Supplier \#8.1)
\end{tabular}


Table 4 (continued)

Data code (1st level)

Storing and accessing information and communication

Business model 2: Care research Collecting patient feedback and surveys

Performing evidence-based research

Performing research trials on (medical) outcomes

Doing contract research

Business model innovation / extension: active and direct patient involvement

Involving patients in tracking disease status " [...] that there is now also the possibility for ALS patients to report their needs directly. [...] which is evaluated by and quality of life

Providing prospective needs-based care the patient via the app, is also displayed graphically in the outpatient partner account." (Care research manager \#2)

"[...] I use the APP to document my status [speech, breathing] every month." (Patient \#13.2)

Representative quotations

"The ATD provider responded within days after the prescription had been passed on to him via APST and arranged a visit to individualize the required device. [...] The medication arrives always a few days after the replenishment order has been issued." (Husband of ALS patient in interview \#13.2)

"So, I think if we join with suppliers, with different institutions, with the health insurance companies, we would have much more possibilities." (Patient representative \#11.1)

"This means that this coordination takes place via APST [...] The supplier knows exactly what kind of wheelchair the patient needs." (Platform employee \#5.1)

"However, in the past we also conducted a survey on robotics with patients." (Care research manager \#2)

"The important aspect is that the quality is right, so a wheelchair must be adjusted to the patient's needs. The communication controls must be customized. Communication equipment and everything that is needed must be adapted. The instruction for all these devices is very important, family members must be able to deal with them and must be trained." (Patient representative \#11.5)

"I think it is right to share my data if it helps other patients." (Patient \#13.1)

"Data generated in the context of care management is used for a systematic analysis of care on the basis of informed patient consent. This results in a 'dual effect': The digitization of care data on the APST Internet portal serves directly to coordinate care and at the same time research into care through the evaluation of 'routine' data (real world evidence)." (Founder \#14)

"On the supply of remedies, on the supply of aids, an idea of what the "ALS' finally costs [...] Here we have precisely these data from the real world evidence, so to speak, and can map these structures much better." (Founder \#1.1)

"Therefore, a distinction is also made between AMG [pharmaceutical] and MPG [medical device] studies [...] and in the latter we actually have such qualitative fields in practice, where patients are not only use scores but also share anecdotes." (Care research manager \#2)

"They are promptly informed, they are informed about all ongoing studies and treatment options, but they are also immediately informed about the risks, on the medication." (Patient representative \#11.3)

"Research on medications can be made possible through biomarkers." (Founder \#9)

"So here we have to expand further, but to do this we also do prospective research directly in contract research, where we also know such questions beforehand and then collect the data accordingly." (Founder \#1.2)

"And the second model is that there are manufacturers such as the Swedish manufacturer of electric wheelchairs who want to learn more about the needs of the patient group." (Founder \#1.2)

"And something completely new is [...] that the patients themselves can communicate their care needs via the app." (Care Research Manager \#2)

"Start the care process before the patient identifies his or her needs." (Supplier \#9)

"I have been contacted by APST suggesting that might wife would benefit from a breathing aid." [husband of ALS patient \#13.1] "I like the flow of information on the platform very much, just this morning I received information about a supporting aid that might become relevant soon.” (Patient \#13.1)

"You have to be patient, but sometimes I get information about devices that could become relevant." (Patient \#13.3)
Funding Open Access funding enabled and organized by Projekt DEAL.

Open Access This article is licensed under a Creative Commons Attribution 4.0 International License, which permits use, sharing, adaptation, distribution and reproduction in any medium or format, as long as you give appropriate credit to the original author(s) and the source, provide a link to the Creative Commons licence, and indicate if changes were made. The images or other third party material in this article are included in the article's Creative Commons licence, unless indicated otherwise in a credit line to the material. If material is not included in the article's Creative Commons licence and your intended use is not permitted by statutory regulation or exceeds the permitted use, you will need to obtain permission directly from the copyright holder. To view a copy of this licence, visit http://creativecommons.org/licenses/by/4.0/.

\section{References}

Aanestad, M., \& Jensen, T. B. (2011). Building nation-wide information infrastructures in healthcare through modular implementation strategies. Journal of Strategic Information Systems, 20(2), 161176. https://doi.org/10.1016/j.jsis.2011.03.006

Aanestad, M., Grisot, M., Hanseth, O., \& Vassilakopoulou, P. (Eds.). (2017). Information infrastructures within European health care. Working with the installed base. Cham: Springer International Publishing.

Abell, D. F. (1980). Defining the business: The starting point of strategic planning. Englewood Cliffs, N.J: Prentice-Hall. 
Alvesson, M., \& Kärreman, D. (2007). Constructing mystery: Empirical matters in theory development. Academy of Management Review, 32(4), 1265-1281.https://doi.org/10.5465/amr.2007.26586822.

Amelung, V. E., Wolf, S., \& Hildebrandt, H. (2012). Integrated care in Germany - A stony but necessary road! International Journal of Integrated Care, 12(1), 1-5. https://dx.doi.org/10.5334\%2Fijic.853

Anderson, N., Potočnik, K., \& Zhou, J. (2014). Innovation and creativity in organizations: A State-of-the-Science Review, Prospective Commentary, and Guiding Framework. Journal of Management, 40(5), 1297-1333. https://doi.org/10.1177/0149206314527128.

Artiga, S., \& Hinton, E. (2018). Beyond health care: The role of social determinants in promoting health and health equity. Issue Report: Henry J Kaiser Family Foundation.

Bakker, M., Creemers, H., Schipper, K., Beelen, A., Grupstra, H., Nollet, F., \& Abma, T. (2015). Need and value of case management in multidisciplinary ALS care: A qualitative study on the perspectives of patients, spousal caregivers, and professionals. Amyotrophic Lateral Sclerosis \& Frontotemporal Degeneration, 16(3-4), 180 186. https://doi.org/10.3109/21678421.2014.971811.

Baldwin, C. Y., \& Woodard, J. C. (2009). The architecture of platforms: A unified view. Cheltenham, U.K. and Northampton: Edward Elgar Publishing.

Brandhorst, A., Hildebrandt, H., \& Luthe, E.-W. (Eds.). (2017). Kooperation und Integration - das unvollendete Projekt des Gesundheitswesens. Wiesbaden: Springer.

Brynjolfsson, E., van Alstyne, M. W., \& Renshaw, A. A. (1997). The matrix of change: A tool for business process reengineering. Sloan Management Reviews, 38(2), 37-54.

Ceccagnoli, M., Forman, C., Huang, P., \& Wu, D. (2012). Co-creation of value in a platform ecosystem: The case of enterprise software. MIS Quarterly, 36(1), 263-290. https://doi.org/10.2307/41410417.

Eisenhardt, K. M. (1989). Building theories from case study research. Academy of Management Review, 14(4), 532-550. https://doi.org/ 10.5465/amr.1989.4308385.

Flyvbjerg, B. (2006). Five misunderstandings about case-study research. Qualitative Inquiry, 12(2), 219-245. https://doi.org/10.1177/ 1077800405284363

Foss, N. J., \& Saebi, T. (2018). Business models and business model innovation: Between wicked and paradigmatic problems. Long Range Planning, 51(1), 9-21. https://doi.org/10.1016/j.lrp.2017. 07.006.

Funke, A., Grehl, T., Grosskreutz, J., Münch, C., Walter, B., Kettemann, D., Karnapp, C., Gajewski, N., Meyer, R., Maier, A., Gruhn, K.M., Prell, T., Kollewe, K., Abdulla, S., Kobeleva, X., Körner, S., Petri, S., \& Meyer, T. (2015). Hilfsmittelversorgung bei der amyotrophen Lateralsklerose. Analyse aus 3 Jahren Fallmanagement in einem internetunterstützten Versorgungsnetzwerk. Nervenarzt, 86(8), 1007-1017. https://doi.org/10.1007/s00115-015-4398-2.

Funke, A., Spittel, S., Grehl, T., Grosskreutz, J., Kettemann, D., Petri, S., Weyen, U., Weydt, P., Dorst, J., Ludolph, A. C., Baum, P., Oberstadt, M., Jordan, B., Hermann, A., Wolf, J., Boentert, M., Walter, B., Gajewski, N., Maier, A., Münch, C., \& Meyer, T. (2018). Provision of assistive technology devices among people with ALS in Germany: A platform-case management approach. Amyotrophic Lateral Sclerosis and Frontotemporal Degeneration, 19(5-6), 342-350. https://doi.org/10.1080/21678421.2018. 1431786.

Fürstenau, D., Auschra, C., Klein, S., \& Gersch, M. (2019). A process perspective on platform design and management: evidence from a digital platform in health care. Electronic Markets, 29(4), 581-596. https://doi.org/10.1007/s12525-018-0323-4.

Gassmann, O., Frankenberger, K., \& Csik, M. (2014). The business model navigator. 55 models that will revolutionise your business. Harlow, England, London, New York, Boston, San Francisco: Pearson.
Gawer, A., \& Cusumano, M. A. (2014). Industry platforms and ecosystem innovation. Journal of Product Innovation Management, 31(3), 417-433. https://doi.org/10.1111/jpim.12105.

Güell, M. R., Antón, A., Rojas-García, R., Puy, C., \& Pradas, J. (2013). Comprehensive care of amyotrophic lateral sclerosis patients: A care model. Archivos de Bronconeumologia, 49(12), 529-533. https:// doi.org/10.1016/j.arbr.2013.09.011.

Guggenberger, T., Möller, F., Boualouch, K., \& Otto, B. (2020). Towards a unifying understanding of digital business models. Proceedings of the 24th Pacific Asia conference on information systems (PACIS).

Haddad, P., Schaffer, J. L., \& Wickramasinghe, N. (2015). Evaluating business value of IT in healthcare: Three clinical practices from Australia and the US. Studies in Health Technology and Informatics, Volume 216: MEDINFO 2015: eHealth-enabled Health, 183-187. https://doi.org/10.3233/978-1-61499-564-7-183.

Hagiu, A., \& Wright, J. (2015). Multi-sided platforms. International Journal of Industrial Organization, 43(11), 162-174. https://doi. org/10.1016/j.ijindorg.2015.03.003.

Harari, Y. N. (2017). Homo Deus. A brief history of tomorrow. London: Vintage.

Hein, A., Schreieck, M., Wiesche, M., Böhm, M., \& Krcmar, H. (2019). The emergence of native multi-sided platforms and their influence on incumbents. Electronic Markets, 29(4), 631-647. https://doi.org/ 10.1007/s12525-019-00350-1.

Hwang, J., \& Christensen, C. M. (2008). Disruptive innovation in health care delivery: A framework for business-model innovation. Health Affairs, 27(5), 1329-1335. https://doi.org/10.1377/hlthaff.27.5. 1329.

ICHOM (2020). International consortium for health outcome measures. Retrieved from https://www.ichom.org.

Irwin, G., Topdijan, J., \& Kaura, A. (2014). Putting an I in healthcare. Strategy+ Business (71), 1-10.

Kazan, E. (2018). Towards a disruptive digital platform model. Copenhagen Business School. PhD series Nr., 25.2018.

Kelly, S., \& Noonan, C. (2017). The doing of datafication (and what this doing does): Practices of edification and the enactment of new forms of sociality in the Indian public health service. Journal of the Association for Information Systems, 18(12), 872-899. https://doi. org/10.17705/1 jais.00477.

Kornberger, M. (2017). The values of strategy: Valuation practices, rivalry and strategic agency. Organization Studies, 38(12), 1753 1773. https://doi.org/10.1177/0170840616685365.

Li, F. (2020). The digital transformation of business models in the creative industries: A holistic framework and emerging trends. Technovation, 92-93, 102012. https://doi.org/10.1016/j. technovation.2017.12.004.

Lincoln, Y. S., \& Guba, E. G. (1985). Naturalistic inquiry. Beverly Hills: Sage.

Locke, K., Golden-Biddle, K., \& Feldman, M. S. (2008). Making doubt generative: Rethinking the role of doubt in the research process. Organization Science, 19(6), 907-918. https://doi.org/10.1287/ orsc. 1080.0398 .

Mai, J.-E. (2016). Big data privacy: The datafication of personal information. The Information Society, 32(3), 192-199. https://doi.org/10. 1080/01972243.2016.1153010.

Mandel, J. C., Kreda, D. A., Mandl, K. D., Kohane, I. S., \& Ramoni, R. B. (2016). SMART on FHIR: A standards-based, interoperable apps platform for electronic health records. Journal of the American Medical Informatics Association, 23(5), 899-908. https://doi.org/ 10.1093/jamia/ocv189.

Mayring, P. (2000). Qualitative content analysis. Forum: Qualitative Social Research, 1(2), art. 20. Retrieved from http://www. qualitative-research.net/index.php/fqs/article/download/1089/2384

Mazzucato, M. (2019). The value of everything: Making and taking in the global economy: Penguin. 
Meyer, T., Grosskreutz, J., Münch, C., Maier, A., Meyer, R., Kettemann, D., \& Grehl, T. (2013). AmbulanzPartner - multiprofessionelles und internet-unterstütztes Versorgungsmanagement bei der ALS. Klinische Neurophysiologie, 44(02), 159-166.

Meyer, R., Spittel, S., Steinfurth, L., Funke, A., Kettemann, D., Münch, C., Meyer, T., \& Maier, A. (2018). Patient-reported outcome of physical therapy in amyotrophic lateral sclerosis: Observational online study. JMIR Rehabilitation and Assistive Technologies, 5(2), e10099. https://doi.org/10.2196/10099.

Meyer, T., Funke, A., Münch, C., Kettemann, D., Maier, A., Walter, B., Thomas, A., \& Spittel, S. (2019). Real world experience of patients with amyotrophic lateral sclerosis (ALS) in the treatment of spasticity using Tetrahydrocannabinol:Cannabidiol (THC:CBD). BMC Neurology, 19(1), 1-13. https://doi.org/10.1186/s12883-019-1443y.

Meyer, T., Kettemann, D., Maier, A., Grehl, T., Weyen, U., Grosskreutz, J., Steinbach, R., Norden, J., George, A., Hermann, A., Guenther, R., Petri, S., Schreiber-Katz, O., Dorst, J., Ludolph, A. C., Walter, B., Münch, C., \& Spittel, S. (2020). Symptomatic pharmacotherapy in ALS: Data analysis from a platform-based medication management programme. Journal of Neurology, Neurosurgery, and Psychiatry, 91(7), 783-785. https://doi.org/10.1136/jnnp-2020322938.

Mini, T., \& Widjaja, T. (2019). Tensions in digital platform business models: A literature review. Proceedings of the 40th International Conference on Information Systems (ICIS), 1-17.

Mitchell, J. D. (2000). Guidelines in motor neurone disease (MND)/ amyotrophic lateral sclerosis (ALS)-from diagnosis to patient care. Journal of Neurology, 247, VI7-VI12. https://doi.org/10.1007/ PL00007786.

Moghimi, H., de Steiger, R., Schaffer, J., \& Wickramasinghe, N. (2013). The benefits of adopting e-performance management techniques and strategies to facilitate superior healthcare delivery: the proffering of a conceptual framework for the context of Hip and Knee Arthroplasty. Health \& Technology, 3(3), 237-247. https://doi.org/ 10.1007/s12553-013-0057-4.

Muzellec, L., Ronteau, S., \& Lambkin, M. (2015). Two-sided internet platforms: A business model lifecycle perspective. Industrial Marketing Management, 45(1), 139-150. https://doi.org/10.1016/j. indmarman.2015.02.012.

Nagasaka, T., \& Takiyama, Y. (2015). Home- and community-based medical care for neurodegenerative diseases: ALS as an illustration. In K. Wada (Ed.), Neurodegenerative disorders as systemic diseases (pp. 237-275). Tokyo: Springer Japan. https://doi.org/10.1007/9784-431-54541-5 11.

Newell, S., \& Marabelli, M. (2015). Strategic opportunities (and challenges) of algorithmic decision-making: A call for action on the long-term societal effects of 'datification'. Journal of Strategic Information Systems, 24(1), 3-14. https://doi.org/10.1016/j.jsis. 2015.02.001.

Osterwalder, A., \& Pigneur, Y. (2013). Business model generation. A handbook for visionaries, game changers, and challengers. New York: Wiley \& Sons

Otto, B., \& Jarke, M. (2019). Designing a multi-sided data platform: Findings from the international data spaces case. Electronic Markets, 29(4), 561-580. https://doi.org/10.1007/s12525-01900362-x.

Parker, G., Van Alstyne, M., \& Jiang, X. (2017). Platform ecosystems: How developers invert the firm. MIS Quarterly, 41(1), 255266. https://doi.org/10.2139/ssrn.2861574.

Porter, M. E. (2001). Strategy and the internet. Advances in Strategy, 79(3), 64-78.

Porter, M. E. (2008). Value-based health care delivery. Annals of Surgery, 248(4), 503-509. https://doi.org/10.1097/SLA. 0b013e31818a43af.
Porter, M. E., \& Guth, C. (2012). Chancen für das deutsche Gesundheitssystem: Von Partikularinteressen zu mehr Patientennutzen. Berlin: Springer Gabler.

Porter, M. E., \& Teisberg, E. O. (2006). Redefining health care. Creating value-based competition on results. Bosten: Harvard Business School Press.

Raivio, Y., \& Luukkainen, S. (2011). Mobile networks as a two-sided platform - case open telco. Journal of Theoretical and Applied Electronic Commerce Research, 6(2), 15-16. https://doi.org/10. 4067/S0718-18762011000200008.

Remane, G., Hanelt, A., Tesch, J. F.A.N., \& Kolbe, L. M. (2017). The business model pattern database - a tool for systematic business model innovation. International Journal of Innovation Management, 21(01), 1750004-1-1750004-61. https://doi.org/10. $1142 / \mathrm{S} 1363919617500049$.

Rochet, J.-C., \& Tirole, J. (2003). Platform competition in two-sided markets. Journal of the European Economic Association, 1(4), 990-1029. https://doi.org/10.1162/154247603322493212.

Sabatier, V., Mangematin, V., \& Rousselle, T. (2010). From recipe to dinner: Business model portfolios in the european biopharmaceutical industry. Long Range Planning, 43(2-3), 431-447. https://doi. org/10.1016/j.lrp.2010.02.001.

Sackett, D. L., Rosenberg, W. M., Gray, J. A., Haynes, R. B., \& Richardson, W. S. (1996). Evidence based medicine: What it is and what it isn't. British Medical Journal, 312(7023), 7172. https://doi.org/10.1136/bmj.312.7023.71.

Schreier, M. (2014). Qualitative content analysis. In U. Flick (Ed.), The SAGE handbook of qualitative data analysis (pp. 170-183). London: Sage.

Seitzer, F., Kahrass, H., Neitzke, G., \& Strech, D. (2016). The full spectrum of ethical issues in the care of patients with ALS: A systematic qualitative review. Journal of Neurology, 263(2), 201-209. https:// doi.org/10.1007/s00415-015-7867-4.

Song, P., Xue, L., Rai, A., \& Zhang, C. (2018). The ecosystem of software platform: A study of asymmetric cross-side network effects and platform governance. MIS Quarterly, 42(1), 121-142.

Soriani, M.-H., \& Desnuelle, C. (2017). Care management in amyotrophic lateral sclerosis. Revue Neurologique, 173(5), 288-299. https:// doi.org/10.1016/j.neurol.2017.03.031.

Strauss, A., \& Corbin, J. M. (1990). Basics of qualitative research: Grounded theory procedures and techniques. Newbury Park, CA: Sage.

Täuscher, K., \& Laudien, S.M. (2018). Understanding platform business models: A mixed methods study of marketplaces. European Management Journal, 36(3), 319-329. https://doi.org/10.1016/j. emj.2017.06.005.

Teece, D. J. (2010). Business models, business strategy and innovation. Long Range Planning, 43(2-3), 172-194. https://doi.org/10.1016/j. lrp.2009.07.003.

Timmers, P. (1998). Business models for electronic markets. Electronic Markets, 8(2), 3-8. https://doi.org/10.1080/10196789800000016.

van Alstyne, M. W., Parker, G. G., \& Choudary, S. P. (2016). Pipelines, Platforms, and the new rules of strategy. Harvard Business Review, 94(4), 54-62.

Vassilakopoulou, P., Grisot, M., Jensen, T. B., Sellberg, N., Eltes, J., Thorseng, A. A., \& Aanestad, M. (2017). Building national eHealth platforms: The challenge of inclusiveness. Proceedings of the 38th International Conference on Information Systems (ICIS).

Vega, J. (2013). Universal health coverage: The Post-2015 development agenda. The Lancet, 381(9862), 179-180.

Wickramasinghe, N., \& Bodendorf, F. (Eds.) (2019). Delivering superior health and wellness management with IoT and analytics. Berlin: Springer.

Wickramasinghe, N., Silvers, J. B., Sloane, E. B., McCoy, M. J., \& Schaffer, J. B. (2019). Data, denial, and disparity: Is this a new digital divide? In N. Wickramasinghe \& F. Bodendorf (Eds.), Delivering superior health and wellness mangament with IoT and analytics (pp. 415-423) Berlin: Springer. 
Xie, C., Bagozzi, R. P., \& Troye, S. V. (2008). Trying to prosume: Toward a theory of consumers as co-creators of value. Journal of the Academy of Marketing Science, 36(1), 109-122. https://doi.org/ 10.1007/s11747-007-0060-2.

Yaraghi, N., Du, A. Y., Sharman, R., Gopal, R. D., \& Ramesh, R. (2015). Health information exchange as a multisided platform: Adoption, usage, and practice involvement in service co-production. Information Systems Research, 26(1), 1-18. https://doi.org/10. 1287/isre.2014.0547.

Yin, R. K. (2018). Case study research: Design and methods (6th ed.). Los Angeles: Sage.
Zenooz, A. M., \& Fox, J. (2019). How new health care platforms will improve patient care. Harvard Business Review, 10(1), 1-8.

Zuboff, S. (2019). The age of surveillance capitalism: The fight for a human future at the new frontier of power (First ed.). New York: PublicAffairs.

Publisher's note Springer Nature remains neutral with regard to jurisdictional claims in published maps and institutional affiliations. 